\title{
A COMPUTERISED IDENTIFICATION KEY FOR 30 GENERA OF PLANT PARASITIC NEMATODES
}

\author{
N.L. BELL \\ AgResearch, Ruakura Research Centre, Private Bag 3123, Hamilton, \\ New Zealand \\ Corresponding author: nigel.bell@agresearch.co.nz
}

\begin{abstract}
A computer-based key for identifying plant parasitic nematodes of temperate agriculture in New Zealand and around the world is described. It uses the Lucid ${ }^{\mathrm{TM}}$ software developed at the University of Queensland and includes images of major diagnostic features. The key is multi-access rather than dichotomous so may be entered at any point, allowing for the most obvious characters of a specimen to be scored first and thereby immediately reduce the number of likely taxa. Both qualitative and quantitative characters are used. The key requires that the specimen can be viewed microscopically, but examples of most morphological terms are illustrated so the non-specialist should be able to make use of the key. Keywords: nematode identification, biosecurity.
\end{abstract}

\section{INTRODUCTION}

Plant parasitic nematodes are important pests of pastures, crops and horticulture. For nematodes already established in New Zealand, accurate identification of specimens is a vital first step in making decisions on control and management options, particularly if the host is a high value crop or if expensive chemical controls are being contemplated. From a biosecurity perspective it is imperative that exotic nematodes, found pre- or post-border can be readily identified and appropriate action taken.

Computerised identification keys have been published for species of plant parasitic nematodes of: the family Pratylenchidae (Ryss 1997a), the genera Ditylenchus (Viscardi \& Brzeski 1993), Radopholus (Ryss 1997b) and Cactodera, Globodera, Heterodera and Punctodera (Viscardi \& Brzeski 1995). Galtsova \& Kulangieva (1995) described a computerised identification system for freeliving nematodes. These keys use a range of software platforms, including spreadsheets. On the internet the University of Nebraska-Lincoln (2002) has an illustrated identification key to plant parasitic and freeliving nematodes that has very good illustrations but omits a number of important plant parasitic genera, including Globodera, Longidorus and Paratrichodorus. Also on the web are illustrated keys to the free-living nematode orders Diplogasterida and Rhabditida and the plant parasitic family Belonolaimidae (Nguyen 2002a, 2002b, 2002c). An electronic version of the Warwick et al. (1998) keys to marine nematode identification has been devised by the Plymouth Marine Laboratory, UK and is available on their website (Plymouth Marine Laboratory 2002).

Many of the computerised keys mentioned above are merely illustrated electronic versions of paper dichotomous keys. The keys built using software such as Lucid ${ }^{\mathrm{TM}}$ are not dichotomous but are multi-access, a function easily handled by computers but more difficult to achieve in paper form. Lucid ${ }^{\mathrm{TM}}$ was developed at the Centre for Pest Information Technology and Transfer, University of Queensland (Norton 2000; Norton et al. 2000).

A multi-access key allows the user to choose characters and character states that they can observe on their specimen while ignoring characters they cannot reliably observe. This avoids the "unanswerable couplet" drawback of dichotomous keys. Once all the character states which can be observed on a specimen have been selected in the key, the user will be left with one or a small number of taxa to which the specimen belongs. Examples of Lucid ${ }^{\mathrm{TM}}$ keys are available from their website (Lucid 2002), along with further explanation of how the software works.

New Zealand Plant Protection 55:287-290 (2002) 
This paper describes a key to plant parasitic nematodes, which utilises the Lucid $^{\mathrm{TM}}$ software, and discusses the possible uses for such a key.

\section{A KEY TO PLANT PARASITIC NEMATODES}

The genera that this key identifies are listed in Table 1. The characters (and their states) used in the identifications are: Stylet knobs or flanges (present/absent); Stylet length $(<20 /$ $20-40 / 40-60 />60 \mu \mathrm{m})$; Body length $(<0.5 /<1 / 1-2 />2 \mathrm{~mm})$; Vulval position $(50 / 55-75 /$ $>75 \%$ ); Stylet shape (straight/ curved); Head shape (offset/ rounded/ flattened); Female body (saccate with tanned cuticle/ saccate without tanned cuticle/ swollen/ vermiform); relaxed body shape (straight/ C-shaped/ curled); Cuticle annulation (smooth/ coarse); Tail shape (pointed/ blunt/ rounded); Oesophagus (overlapping intestine/ not overlapping intestine); and Median oesophageal bulb (present/ absent). The key is not designed to include males. In some cases males will key out correctly but this is obviously not so for genera with a large degree of sexual dimorphism, such as Meloidogyne.

TABLE 1: Genera identified by the computerised key, their damage potential and presence in New Zealand. Presence/ absence data follow Knight et al. (1997).

\begin{tabular}{|c|c|c|}
\hline Genera & Damage potential & Present in New Zealand? \\
\hline Anguina & Moderate & $\mathrm{Y}$ \\
\hline Aphelenchoides & Moderate-High & $\mathrm{Y}$ \\
\hline Belonolaimus & Moderate-High & $\mathrm{N}$ \\
\hline Bursaphelenchus & Low-High & $\mathrm{Y}^{1}$ \\
\hline Criconema & Low-Moderate & $\mathrm{Y}$ \\
\hline Ditylenchus & Low-Moderate & $\mathrm{Y}$ \\
\hline Dolichodorus & Moderate-High & $\mathrm{N}$ \\
\hline Globodera & High & $\mathrm{Y}$ \\
\hline Gracilacus & Low & $\mathrm{Y}$ \\
\hline Helicotylenchus & Low-Moderate & $\mathrm{Y}$ \\
\hline Hemicycliophora & Low-Moderate & $\mathrm{Y}$ \\
\hline Heterodera & High & $\mathrm{Y}$ \\
\hline Hoplolaimus & Low-Moderate & $\mathrm{N}$ \\
\hline Longidorus & High & $\mathrm{Y}$ \\
\hline Meloidogyne & High & $\mathrm{Y}$ \\
\hline Mesocriconema & Low-Moderate & $\mathrm{Y}$ \\
\hline Naccobus & High & $\mathrm{N}$ \\
\hline Paratrichodorus & Low-Moderate & $\mathrm{Y}$ \\
\hline Paratylenchus & Low-Moderate & $\mathrm{Y}$ \\
\hline Pratylenchus & Moderate & $\mathrm{Y}$ \\
\hline Radopholus & Moderate & $\mathrm{Y}^{2}$ \\
\hline Rotylenchulus & Moderate-High & $\mathrm{N}$ \\
\hline Rotylenchus & Moderate & $\mathrm{Y}$ \\
\hline Scutellonema & Moderate & $\mathrm{Y}$ \\
\hline Subanguina & Moderate & $\mathrm{Y}$ \\
\hline Trichodorus & Low-Moderate & $\mathrm{Y}$ \\
\hline Tylenchorhynchus & Low & $\mathrm{Y}$ \\
\hline Tylenchulus & Moderate-High & $\mathrm{Y}$ \\
\hline Tylenchus sens lat & Low & $\mathrm{Y}$ \\
\hline Xiphinema & High & $\mathrm{Y}$ \\
\hline
\end{tabular}

${ }^{1}$ The pine tree damaging species B. xylophilus is not present in New Zealand.

${ }^{2}$ The banana and citrus parasites $R$. similis and $R$. citrophilus are not present in New Zealand. 
Nematode genera were scored against the character states using the following scores: common; rare; uncertain; commonly misinterpreted; or rarely misinterpreted. Lucid ${ }^{\mathrm{TM}}$ then compiled the key using a score matrix. Also included in the key are images of characters or character states along with some of the genera. Many of these images are reproduced from the "NemaPix" CD of Eisenback \& Zunke (1997). A website is available for the distribution of keys over the internet and the possibility of using this will be explored for the current key. Lucid ${ }^{\mathrm{TM}}$ also has the capability to add subkeys and it may be that future development of the key would allow for species identifications to be added to some genera.

\section{USES FOR THE KEY}

The key described here was originally created for use in the Nematology Laboratory, AgResearch, for identification of plant parasitic nematodes from soil. However, it has become apparent that the key may be useful to other specialists and possibly to teaching institutions either as an identification tool or as a means to illustrate the diversity within the genera of plant parasitic nematodes.

From Table 1 it is apparent that some of the genera of plant parasitic nematodes that are currently not present in New Zealand have the potential to cause damage if they were introduced so they may be of high biosecurity importance. Closer scrutiny of the biology and host plants of species of these genera would be required to determine priorities in biosecurity terms. Along with genera not currently present in New Zealand, there are a number of species from genera already present here which could cause moderate to high production losses were they to be introduced. Prompt and accurate identification of these nematodes pre- or post-border is essential to minimise damage to production or export markets that would follow the importation of unwanted plant parasitic nematodes. The key described here may be of use in this capacity for both nematode specialists and border control personnel.

\section{ACKNOWLEDGEMENTS}

The author thanks the generosity of Drs Eisenback and Zunke in freely allowing the use of their collected images. The author also thanks Ian Popay, Chris Mercer and Karen Knight for their comments on an earlier version of the manuscript.

\section{REFERENCES}

Eisenback, J.D.; Zunke, U. ed. 1997: NemaPix: A journal of nematological images. Volume 1. Mactode Publications, Blacksburg, Virginia, USA.

Galtsova, V.V.; Kulangieva, K V. 1995: Expert system for identification of freeliving nematodes. Ninth International Meiofauna Conference, Palais des Congres, Perpignan, France: 62.

Knight, K.W.L.; Barber, C.J.; Page, G.D. 1997: Plant-parasitic nematodes of New Zealand recorded by host association. J. Nematol. 29: 640-656.

Lucid 2002: Welcome to Lucidcentral.com. www.lucidcentral.com. (2/05/02).

Nguyen, K.B. 2002a: Soil and water nematode identification: Order Diplogasterida. www.ifas.ufl.edu/ kbn/gaster/dipmain.htm. (5/03/02).

Nguyen, K.B. 2002b: Nematode identification: Rhabditida-Rhabditina. www.ifas.ufl.edu/ $\sim \mathrm{kbn} / \mathrm{rhabdi} /$ rhabmain.htm. $(5 / 03 / 02)$.

Nguyen, K.B. 2002c: Nematode identification: Tylenchida. www.ifas.ufl.edu/ kbn/ tylench/TYLENCHIDA.HTM. (5/03/02).

Norton, G.A. 2000: Multi-media keys for identification and diagnostics: the LucID experience. International Workshop of the Asia-Pacific Advanced Network (APAN) and its Applications: 27-30.

Norton, G.A.; Patterson, D.J.; Schneider, M. 2000: LucID: a multi-media educational tool for identification and diagnostics. In: CAL-laborate - A collaborative publication 
on the use of Computer Aided Learning for tertiary level life sciences. UniServe Science, University of Sydney, Sydney, Australia. Pp. 15-18.

Plymouth Marine Laboratory 2002: The Darwin nematode project. www.pml.ac.uk/ nematode. $(2 / 05 / 02)$.

Ryss, A. 1997a: Computerized identification of the plant nematodes of the family Pratylenchidae. Mededelingen Faculteit Landbouwkundige en Toegepaste Biologische Wetenschappen, Universiteit Gent 62: 701-711.

Ryss, A. 1997b: Computerized identification of species of the genus Radopholus (Tylenchida: Pratylenchidae). Russian J. Nematol. 5: 137-142.

University of Nebraska-Lincoln 2002: Interactive Diagnostic Key to Plant Parasitic, Freeliving and Predaceous Nematodes. www.nematode.unl.edu/nemakey.htm (5/ 03/02).

Viscardi, T.; Brzeski, M.W. 1993: DITYL: computerized key for species identification of Ditylenchus (Nematoda: Anguinidae). Fundamental Appl. Nematol. 16: 389392.

Viscardi, T.; Brzeski, M.W. 1995: Computerized key for eelworms identification. Materialy Sesji Instytutu Ochrony Roslin 35: 374-375.

Warwick, R.M.; Platt, H.M.; Somerfield, P.J. 1998: Free-living marine nematodes, Part III. British Monhysterids. Shrewsbury, Field Studies Council. 296 p. 